Supporting information for:

\title{
Scaffold Hopping Transformations Using Auxiliary Restraints for Calculating Accurate Relative Binding Free Energies
}

Junjie Zou, Zhipeng Li, Shuai Liu, Chunwang Peng, Dong Fang, Xiao Wan, Zhixiong Lin, Tai-Sung Lee, Daniel P. Raleigh, Mingjun Yang, Carlos Simmerling 
Table S1. PDB code for the complexes used for free energy calculations.

\begin{tabular}{|c|c|}
\hline Ligands & PDB \\
\hline acyclic & \\
\hline Chk1 $1,17,19,20,21$ & $3 u 9 n^{1}$ \\
\hline FacX edo, $4 \mathrm{c}, 4 \mathrm{~d}$ & $2 \mathrm{ei} 8^{2}$ \\
\hline Tpsb 1,2 & $3 \mathrm{v} 7 \mathrm{t}^{3}$ \\
\hline Bace1 6,7,31 & $4 \mathrm{zsq}^{4}$ \\
\hline Era $2 d, 2 e, 3 b$ & $2 q 70^{5}$ \\
\hline CatS $1 \sim 2$ & $5 \mathrm{qcb}^{6}$ \\
\hline \multicolumn{2}{|l|}{ Macrocycles } \\
\hline 1,2 & $2 \mathrm{pvn}^{7}$ \\
\hline 3,4 & $2 \mathrm{~b} 8 \mathrm{v}^{8}$ \\
\hline $5-7$ & 5 ant $^{9}$ \\
\hline $8-11$ & $2 \mathrm{e} 9 \mathrm{p}^{10}$ \\
\hline $12-16$ & $3 \mathrm{rkz}^{11}$ \\
\hline $19-23$ & $2 \mathrm{q} 15^{12}$ \\
\hline $24-33$ & $3 \mathrm{vha}^{13}$ \\
\hline \multicolumn{2}{|l|}{ Proline mutations } \\
\hline CHYM/OMTKY3 & $1 \mathrm{cho}^{14}$ \\
\hline SGPB/OMTKY3 & $1 \operatorname{sgr}^{15}$ \\
\hline HLE/OMTKY3 & $1 \mathrm{ppf}^{16}$ \\
\hline CARL/OMTKY3 & $1 \mathrm{r} 0 \mathrm{r}^{17}$ \\
\hline
\end{tabular}


Table S2. $\Delta \Delta \mathrm{G}$ values for the example ring opening/closure, ring and chain contraction/expansion transformations calculated using the auxiliary restraints method. $\Delta \Delta \mathrm{G}$ values calculated using standard Amber $18^{18}$, calculated using the XFEP platform ${ }^{19}$ and measured by experiments were compared. Units are $\mathrm{kcal} / \mathrm{mol}$.

\begin{tabular}{llll}
\hline Pairs & $\begin{array}{l}\text { Auxiliary } \\
\text { restraints/GAFF2/ } \\
\text { Standard AMBER }\end{array}$ & $\begin{array}{l}\text { Auxiliary } \\
\text { restraints/GAFF2/ } \\
\text { XFEP }\end{array}$ & Experimental \\
& $-0.41 \pm 0.11$ & $-0.59 \pm 0.16$ & -0.51 \\
\hline CHK1 20 $\rightarrow 17$ & $-1.87 \pm 0.44$ & $-1.34 \pm 0.40$ & -1.78 \\
ER $3 \mathrm{~b} \rightarrow 2 \mathrm{~d}$ & $0.45 \pm 0.36$ & $0.30 \pm 0.08$ & 0.26 \\
CatS $35 \rightarrow 132$ & 0.13 & 0.19 & \\
\hline MUE & &
\end{tabular}


Table S3. Contribution from the bond + angle + dihedral terms to the total $\Delta \Delta \mathrm{G}$. (Units: $\mathrm{kcal} / \mathrm{mol}$ )

\begin{tabular}{llll}
\hline Pairs & $\begin{array}{l}\Delta \mathrm{G} \text { (bond+angle } \\
+ \text { dihedral) }\end{array}$ & Pairs & $\begin{array}{l}\Delta \mathrm{G} \text { (bond+angle } \\
+ \text { dihedral) }\end{array}$ \\
\hline CHK1 21 $\rightarrow 19$ & $0.07 \pm 0.55$ & CHK1 21 $\rightarrow 20$ & $-0.67 \pm 0.10$ \\
CHK1 21 $\rightarrow 17$ & $0.35 \pm 0.16$ & ER $\alpha$ 3b $\rightarrow$ 2d & $-0.71 \pm 0.15$ \\
CHK1 $1 \rightarrow 19$ & $-0.52 \pm 0.10$ & ER $3 \mathrm{~b} \rightarrow 2 \mathrm{e}$ & $0.59 \pm 0.19$ \\
CHK1 20 $\rightarrow 17$ & $0.37 \pm 0.11$ & CatS 35 $\rightarrow 132$ & $0.55 \pm 0.06$ \\
CHK1 1-i $\rightarrow 17$ & $-0.18 \pm 0.03$ & & \\
FacX edo $\rightarrow$ 4d & $-2.37 \pm 0.70$ & & \\
FacX edo $\rightarrow$ 4c & $-1.93 \pm 0.91$ & & \\
TPSB2 2 $\rightarrow 1-11$ & $-2.89 \pm 0.15$ & & \\
BACE-1 7 $\rightarrow 6$ & $-1.13 \pm 1.13$ & & \\
BACE-1 $7 \rightarrow 31$ & $-1.30 \pm 1.43$ & & \\
\hline
\end{tabular}

Uncertainties were calculated as the standard deviation of the three independent runs. 
Table S4. Contribution from the bond+angle+dihedral terms to the total $\Delta \Delta \mathrm{G}$ for macrocycles. (Units: kcal/mol)

\begin{tabular}{ll}
\hline Pairs & $\begin{array}{l}\Delta G \\
\text { (bond+angle_dihedral) }\end{array}$ \\
\hline $\begin{array}{ll}\text { Macrocyclization } \\
1 \rightarrow 2\end{array}$ & $0.39 \pm 0.37$ \\
$3 \rightarrow 4$ & $-1.67 \pm 0.46$ \\
$5 \rightarrow 7$ & $0.13 \pm 1.10$ \\
$6 \rightarrow 7$ & $-1.37 \pm 0.37$ \\
$19 \rightarrow 22$ & $-1.14 \pm 0.23$ \\
$19 \rightarrow 23$ & $-2.61 \pm 0.55$ \\
$33 \rightarrow 30$ & $-1.20 \pm 0.43$ \\
$33 \rightarrow 31$ & $-1.92 \pm 0.79$
\end{tabular}

\begin{tabular}{ll}
\hline Addition of sub-ring & \\
$16 \rightarrow 13$ & $-0.11 \pm 0.39$ \\
$16 \rightarrow 15$ & $0.85 \pm 0.91$ \\
$27 \rightarrow 30$ & $-0.24 \pm 0.84$ \\
$29 \rightarrow 32$ & $-3.54 \pm 0.14$
\end{tabular}

Contraction of ring size

$10 \rightarrow 9$

$11 \rightarrow 10$

$11 \rightarrow 9$

$13 \rightarrow 12$

$14 \rightarrow 12$

$14 \rightarrow 13$

$22 \rightarrow 20$

$22 \rightarrow 21$

$22 \rightarrow 23$

$25 \rightarrow 24$

$26 \rightarrow 24$

$26 \rightarrow 25$

$26 \rightarrow 27$

$28 \rightarrow 27$

$29 \rightarrow 28$

$31 \rightarrow 30$

$32 \rightarrow 31$

$8 \rightarrow 9$
$0.32 \pm 0.25$

$0.42 \pm 0.14$

$-0.76 \pm 1.30$

$3.95 \pm 0.54$

$3.86 \pm 0.21$

$5.52 \pm 0.73$

$2.81 \pm 1.56$

$2.02 \pm 1.43$

$1.79 \pm 1.62$

$2.20 \pm 0.47$

$3.65 \pm 1.42$

$0.36 \pm 0.38$

$0.90 \pm 1.61$

$0.84 \pm 0.06$

$0.35 \pm 0.90$

$2.70 \pm 0.61$

$2.06 \pm 0.99$

$0.05 \pm 0.23$

Uncertainties were calculated as the standard deviation of the three independent runs. 
Table S5. Contribution from the bond + angle + dihedral terms to the total $\Delta \Delta \mathrm{G}$ for core fragment analogs in relative hydration free energy calculations. (Units: $\mathrm{kcal} / \mathrm{mol}$ )

\begin{tabular}{ll}
\hline Pairs & $\begin{array}{l}\Delta \mathrm{G} \text { (bond+angle }+ \\
\text { dihedral) }\end{array}$ \\
\hline CHK1 21 $\rightarrow 19$ & $-1.74 \pm 0.22$ \\
CHK1 21 $\rightarrow 17$ & $0.89 \pm 0.60$ \\
CHK1 1 $\rightarrow 19$ & $0.38 \pm 0.11$ \\
CHK1 20 $\rightarrow 17$ & $0.69 \pm 0.10$ \\
CHK1 1-i $\rightarrow 17$ & $0.16 \pm 0.16$ \\
FacX edo $\rightarrow$ 4c & $0.45 \pm 0.01$ \\
TPSB2 2 $\rightarrow 1-$ ii & $1.27 \pm 0.02$ \\
BACE-1 7 $\rightarrow 6$ & $0.48 \pm 0.09$ \\
CHK1 21 $\rightarrow$ 20 & $2.04 \pm 0.06$ \\
ER 2 3b $\rightarrow$ 2e & $-1.51 \pm 0.06$ \\
CatS 35 $\rightarrow 132$ & $-0.70 \pm 0.01$ \\
\hline
\end{tabular}

Uncertainties were calculated as standard deviation of the three independent runs. 

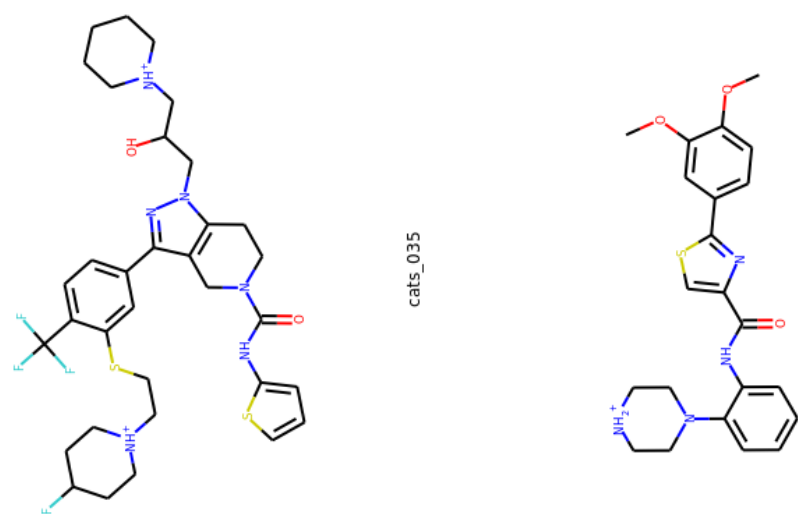

군
흔

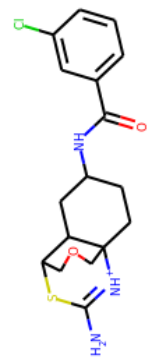

商
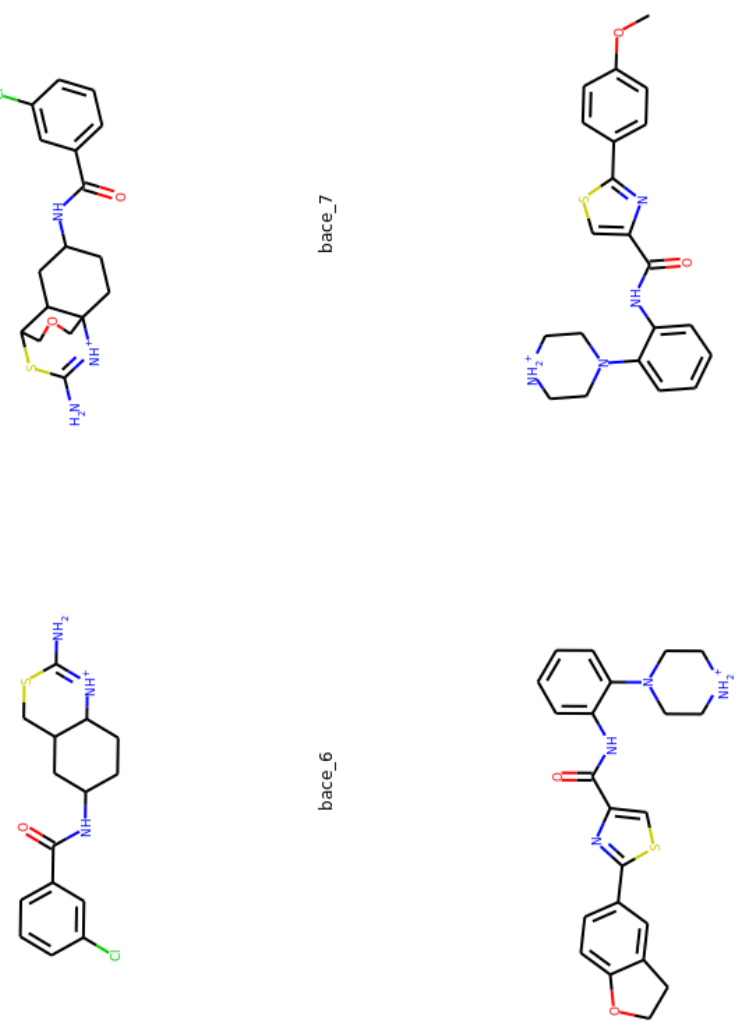

豙<smiles>C[C@@H]1CCC2CC(CC(=O)c3cccc(O)c3)CC[C@@H]2C1</smiles><smiles></smiles> 

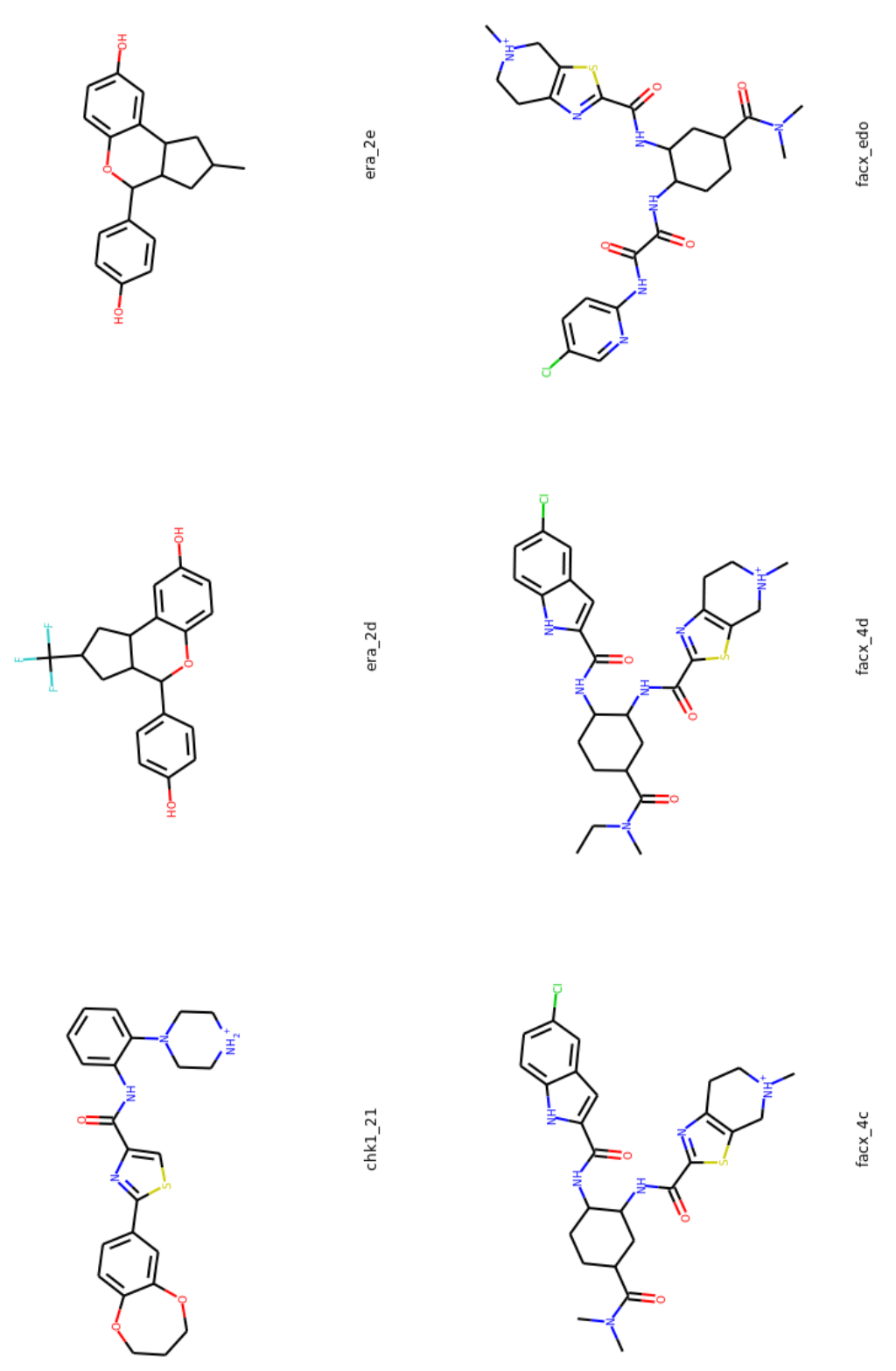

高

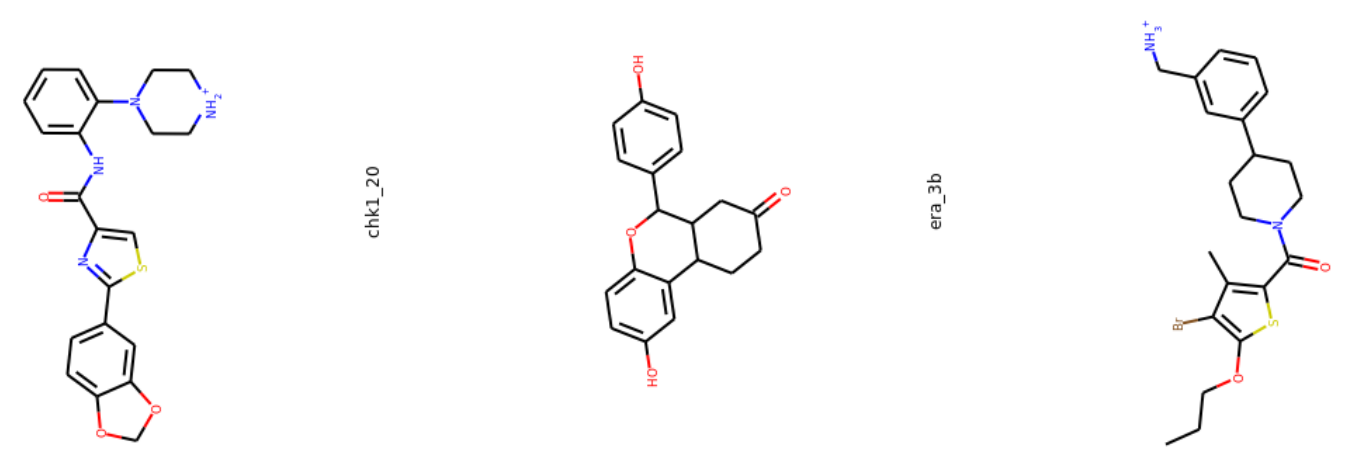



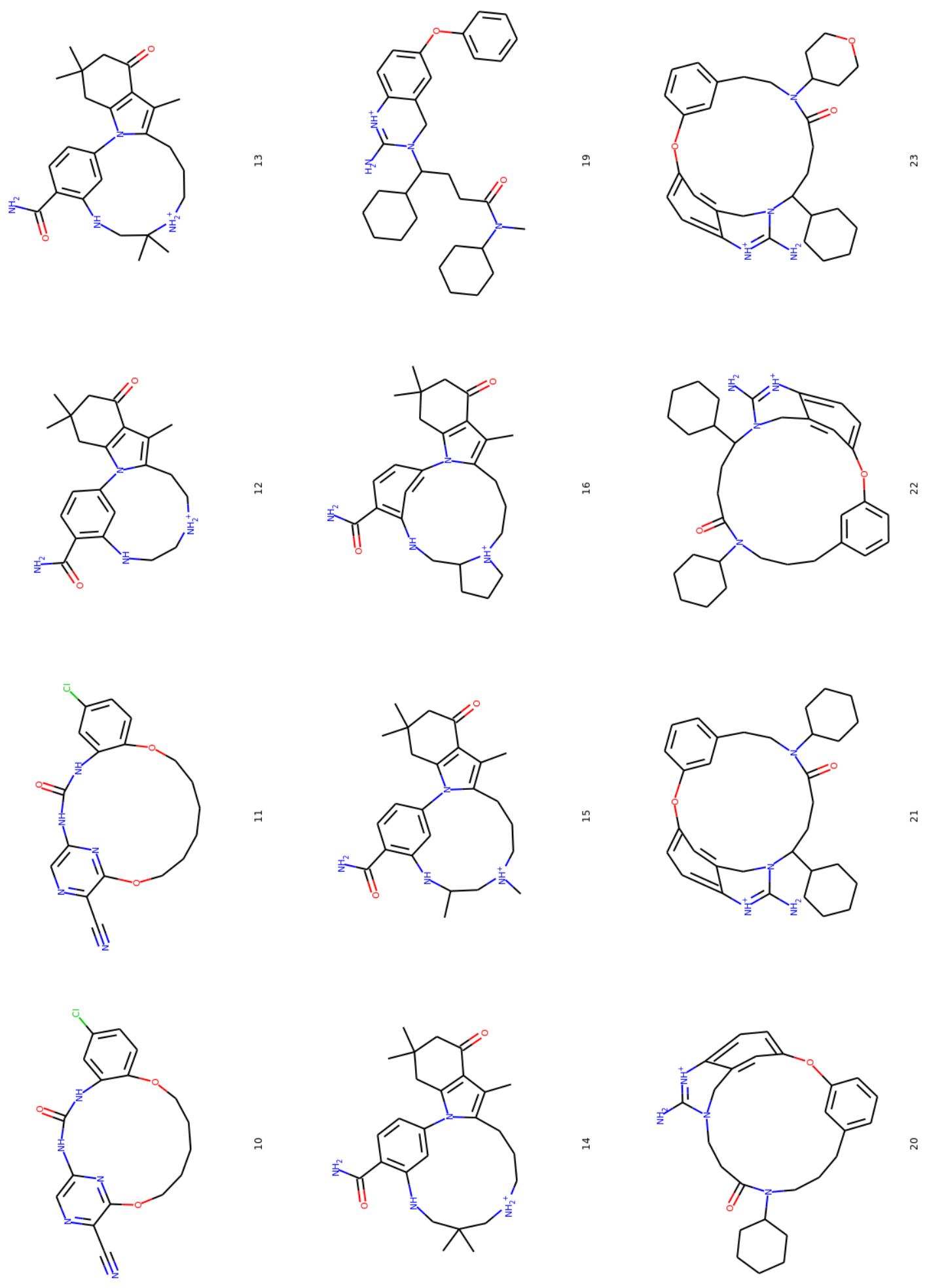

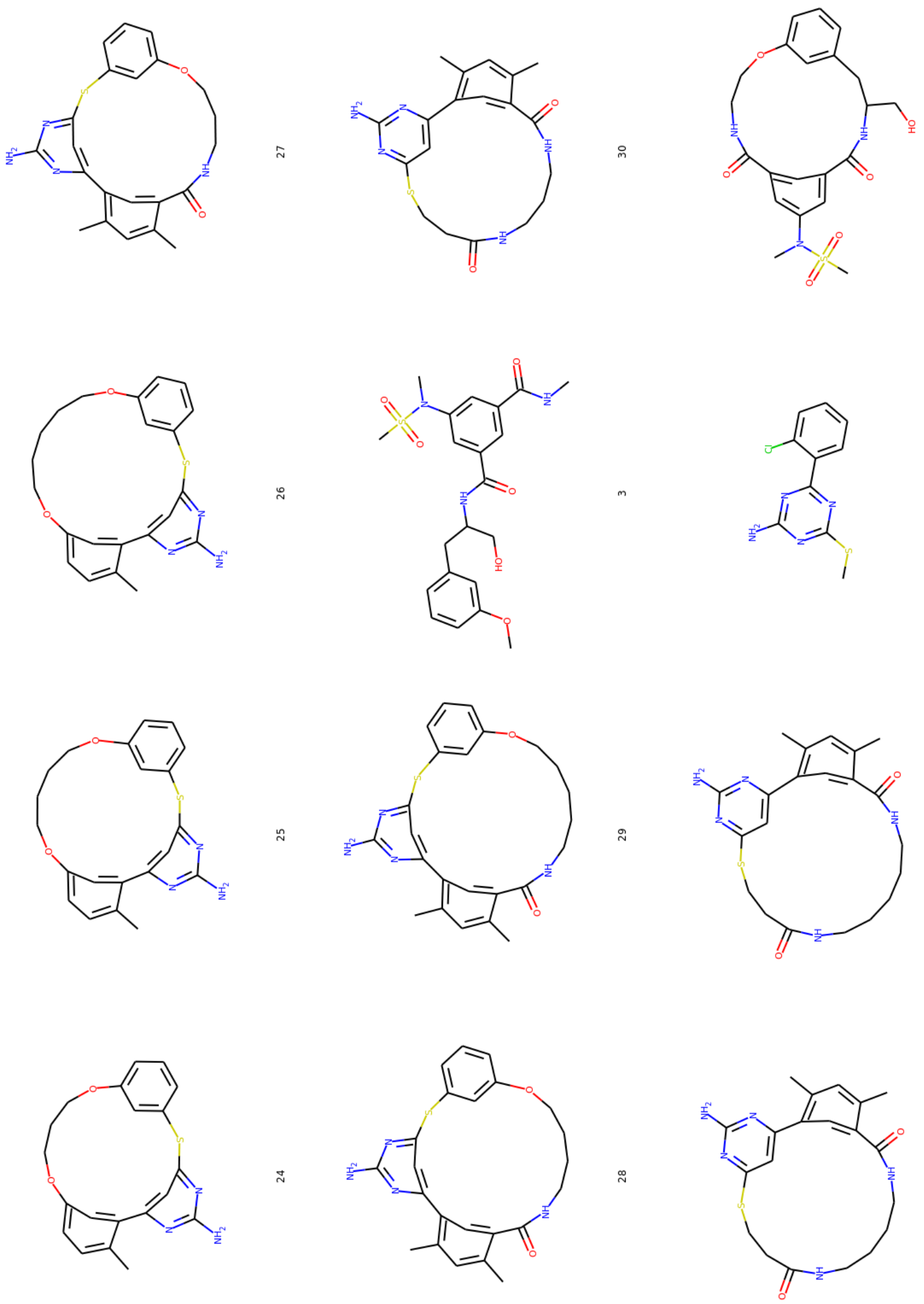

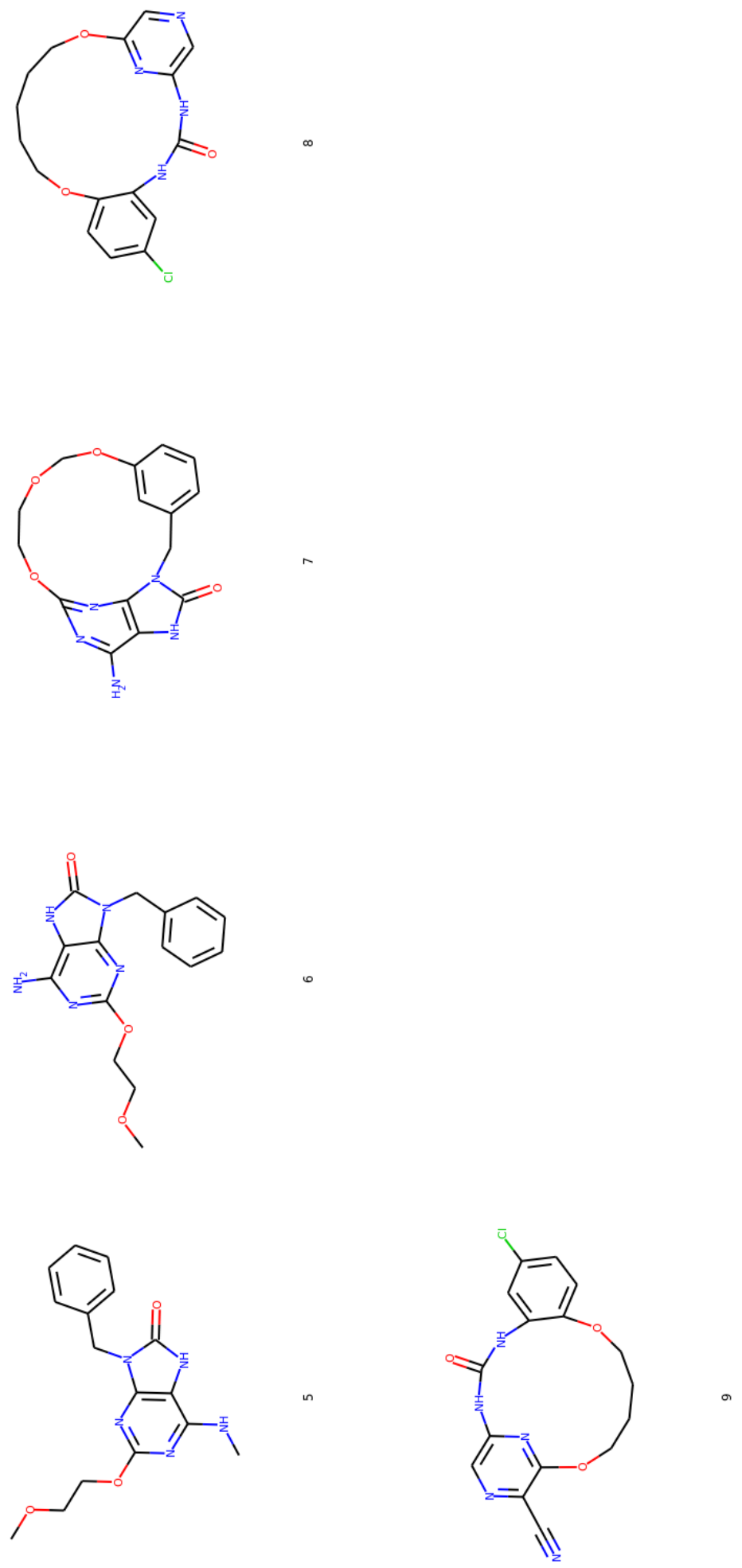

Figure S1. 2D structures for the studied compounds. 


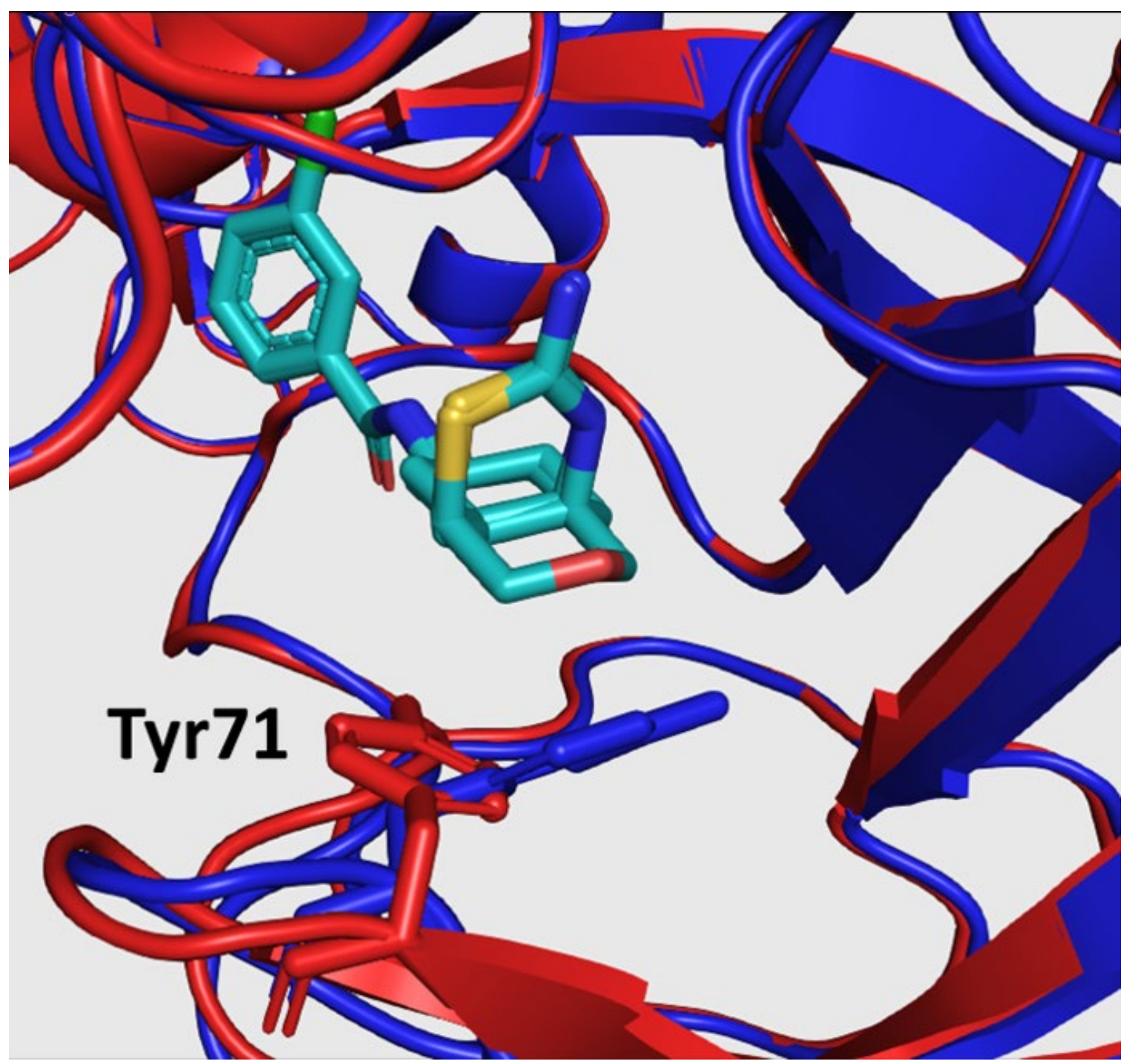

Figure S2. Structures of the complex Bace1/ligand 7 (red 4zsq) and Bace1/ligand 6 (blue 4zsp $)^{4}$. Ligand 7, ligand 6 and Tyr71 are displayed as licorice. The protein backbones are displayed as cartoon. 

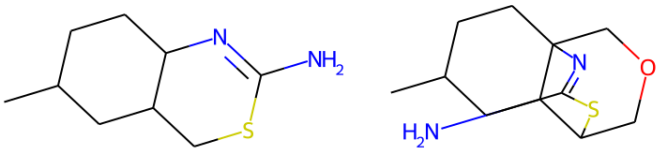

bace_6_frag
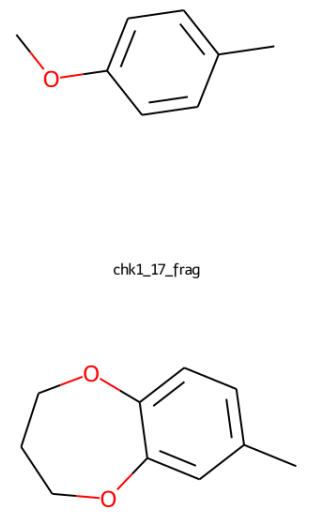

chk1_21_frag

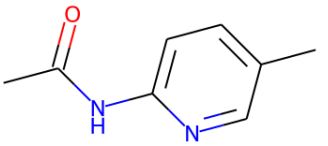

fax_edo_frag

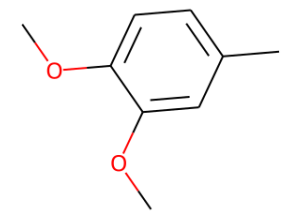

chk1_19_frag

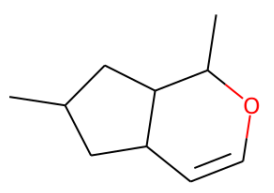

era_2e_frag

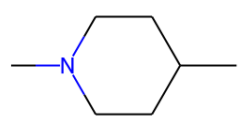

tpsb2_1_frag

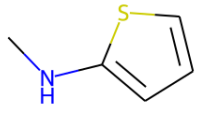

cats1_frag

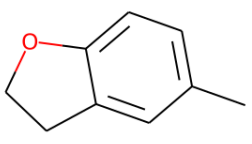

chk1_1_frag<smiles>CC1OC=CC2CCC(=O)CC21</smiles>

era_3b_frag

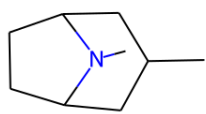

tpsb2_2_frag

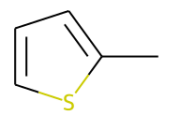

cats2_frag

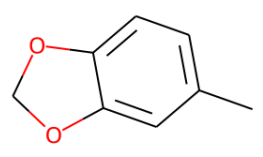

chk1_20_frag

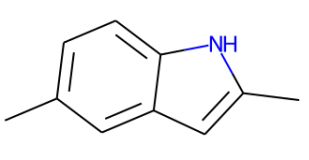

fax_4c_frag

Figure S3. 2D structures for the core fragment analogs. 


\section{Examples of ring opening, ring and linker contraction transformations using standard AMBER18}

Input and output files for $\mathrm{CHK} 120$ to $17, \mathrm{ER} \alpha 3 \mathrm{~b}$ to $2 \mathrm{~d}$ and $\mathrm{CatS} 35$ to 132 are provided to illustrate the ring opening, ring and linker contraction transformations using standard AMBER $18^{18}$. The protocol for the system preparation and equilibration was adopted from the previous study ${ }^{20-21}$. More information can be found in the folders containing the input and output files.

For all three examples, breaking/forming of bonds and applying/releasing of auxiliary restraints were accomplished by modifying bonded interactions using ParmEd ${ }^{22}$. The ParmEd commands, setBond, deleteBond, setAngle, deleteDihedral and addDihedral were used to change bonded interactions in the Amber parm7 files. By changing the bonded interaction parameters in the selected TI regions, the free energy of breaking/forming of bonds and applying/releasing of auxiliary restraints will be accounted as free energy contributed by the bond, angle and dihedral interactions. The contribution will be reflected in the values of DV/DL in the output file of pmemd. TI regions can be prepared as instructed by $\operatorname{Ref}^{21}$, which is the same as the regular relative free energy calculations.

ParmEd based scripts named prm.sh are given for all examples to show how the auxiliary restraints can be applied if using Amber. Lines for breaking/forming of bonds and applying/releasing of auxiliary restraints were indicated by comments in prm.sh. All prm.sh were prepared in such way that they ensure the Hamiltonians for the end of the $1^{\text {st }}$ stage are exactly the same are the Hamiltonians for the start of the $2^{\text {nd }}$ stage.

\section{Ring opening transformation}

For the ring opening transformation from CHK1 20 to 17 (Fig. S4), H110 was appended onto the molecule as a dummy atom (timerge.sh and alc.py). Two perturbation stages were constructed to carry out the transformation. The $1^{\text {st }}$ stage $\left(\mathbf{1}^{\text {st }} /\right)$ involves perturbing the nonbonded interactions and applying the auxiliary dihedral restraints. All bonded interactions involving $\mathrm{O} 3$ and $\mathrm{C} 22$ were removed, but atom pairs $\mathrm{O} 3-\mathrm{C} 22, \mathrm{O} 3-\mathrm{C} 23, \mathrm{O} 3-\mathrm{C} 18$ and $\mathrm{O} 3-$ H110 remain in the non-bonded interaction exclusion list by setting dummy bonded interactions between these atom pairs. The dummy bonded interactions have zero force constants, but the atoms participating in the same dummy bonded interaction were put in the exclusion list. This avoids abrupt non-bonded interactions as removing the bonded interactions in AMBER also changes the exclusion list. In the $2^{\text {nd }}$ stage $\left(2^{\text {nd }} /\right)$, the dummy bonded interactions and the auxiliary restraints were removed. For CHK1 20 to 17, atom $\mathrm{O} 3$ is far enough from atom $\mathrm{C} 18, \mathrm{C} 22, \mathrm{C} 23$ and $\mathrm{H} 110$ after the $1^{\text {st }}$ stage. Thus, the removal of the dummy bonded interactions does not cause abrupt non-bonded interactions. For a more general application, the change of the exclusion list can happen after the removal of auxiliary dihedral restraints when the atoms involved in the broken bond are far from each

other. Change of non-bonded interactions, application of dummy bonded interactions and application/removal of dihedral restraints were all initialized by changing parameters using prm.sh under each stage. 
Using prm_control.sh instead of prm.sh can prepare the control calculation without auxiliary restraints described in the main text. The only difference between prm_control.sh and prm.sh is that during the $1^{\text {st }}$ stage of contraction, no auxiliary restraints were applied on the ring. Random crashes during HREMD were encountered for this control setup.

After preparing the system following the previous steps (001.setup/), equilibration (002.eq/), relaxation (003.prod/relax/) and production (003.prod/) can be conducted. $\Delta \Delta \mathrm{G}$ values can be obtained from the free energy calculations in the complex state (com/) and the monomer state of ligand (mono/).

The following lambda values were used for CHK1 20 to 17:

$$
\begin{aligned}
& 1^{\text {st }} \text { stage: } \quad 0.0000 .047940 .115050 .206340 .316080 .437380 .562620 .683920 .79366 \\
& 0.884950 .952060 .990780 .9951 .0
\end{aligned}
$$

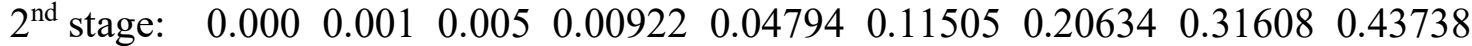

$$
\begin{aligned}
& 0.562620 .683920 .793660 .884951 .0
\end{aligned}
$$




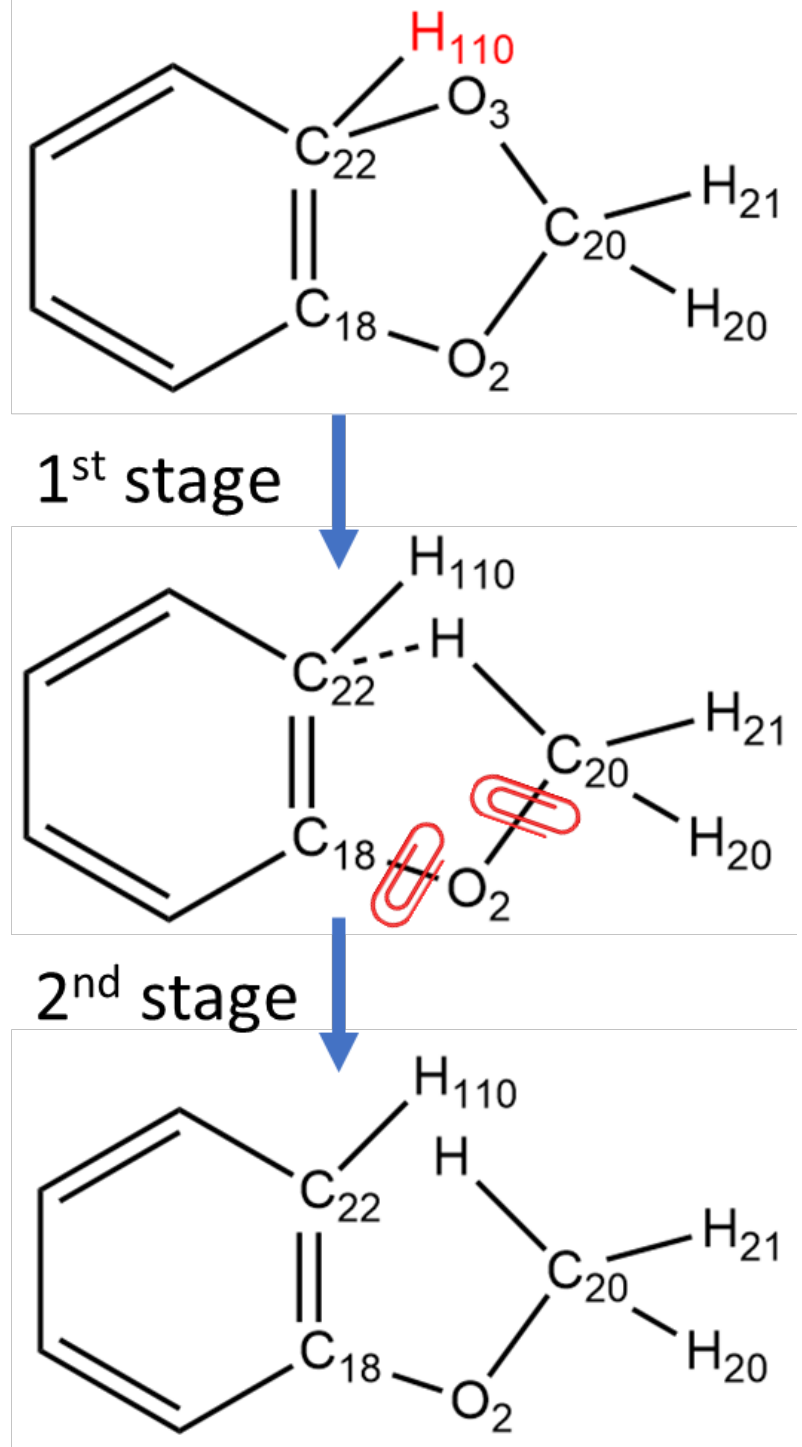

Figure S4. The two stages of perturbations for the ring opening transformation CHK1 20 $->17 . \mathrm{H} 110$ in red indicates that it is originally attached to the molecule as a dummy atom. The dashed line indicates the dummy bonded interaction. Atom $\mathrm{O} 3$ was perturbed into a hydrogen atom by changing its non-bonded interactions. The red clips indicate the two auxiliary dihedral restraints on C22-C18-O2-C20 and C18-O2-C20-O3(H).

\section{Ring contraction transformation}

For the ring contraction transformation from ER $\alpha 3$ b to 2 d (Fig. S5), F1, F2, F3 and H201 were appended onto the molecule as dummy atoms (timerge.sh and alc.py). Two perturbation stages were constructed for the ring contraction transformation from ER $\alpha 3 \mathrm{~b}$ to $2 \mathrm{~d}$. The $1^{\text {st }}$ stage $\left(\mathbf{1}^{\text {st }} /\right)$ involves perturbation of non-bonded interactions. The C19, H17 and $\mathrm{H} 18$ atoms to be removed and contracted were perturbed into dummy atoms without non-bonded interactions, however, no bond was broken or formed in the $1^{\text {st }}$ stage. The $1^{\text {st }}$ stage can be considered as a regular R-group perturbation without breaking and forming 
the covalent bonds. The $\lambda$ values of the $1^{\text {st }}$ stage did not approach exact 1.0 , but this has proven to be sufficient for handling R-group perturbations in our previous studies ${ }^{23-24}$, including the blinded predictions in the Grand Challenge 4 of D3R (Drug Design Data and Resource). The breaking and forming of bonds were carried out in the $2^{\text {nd }}$ stage $\left(2^{\text {nd }} /\right)$. The breaking and forming of bonds were fully conducted as the $\lambda$ values approached exact 0.0 and 1.0 in the $2^{\text {nd }}$ stage. Non-bonded interactions of atom F1, F2, F3 and H201 were turned on during the $2^{\text {nd }}$ stage as well. Change of non-bonded interactions, breaking of bonds and application of bond/angle restraints were all initialized by changing parameters using prm.sh under each stage.

Using prm_control.sh instead of prm.sh can prepare the control calculation without auxiliary restraints described in the main text. The only difference between prm_control.sh and prm.sh is that during the $2^{\text {nd }}$ stage of contraction, bond a2-a3 was broken and bond a1-a3 was formed without any restraints. The control setup crashes at relaxation.

After preparing the system following the previous steps (001.setup/), equilibration (002.eq/), relaxation (003.prod/relax/) and production (003.prod/) can be conducted. $\Delta \Delta \mathrm{G}$ values can be obtained from the free energy calculations in the complex state (com/) and the monomer state of ligand (mono/).

The following lambda values were used for ER $\alpha 3 b$ to $2 d$ :

$$
\begin{aligned}
& 1^{\text {st }} \text { stage: } \quad 0.0000 .009220 .047940 .115050 .206340 .316080 .437380 .562620 .68392 \\
& 0.793660 .884950 .952060 .990780 .9950 .999
\end{aligned}
$$

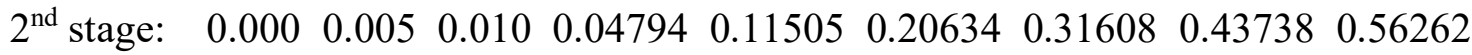

$$
\begin{aligned}
& 0.683920 .793660 .884950 .952060 .990781 .0
\end{aligned}
$$




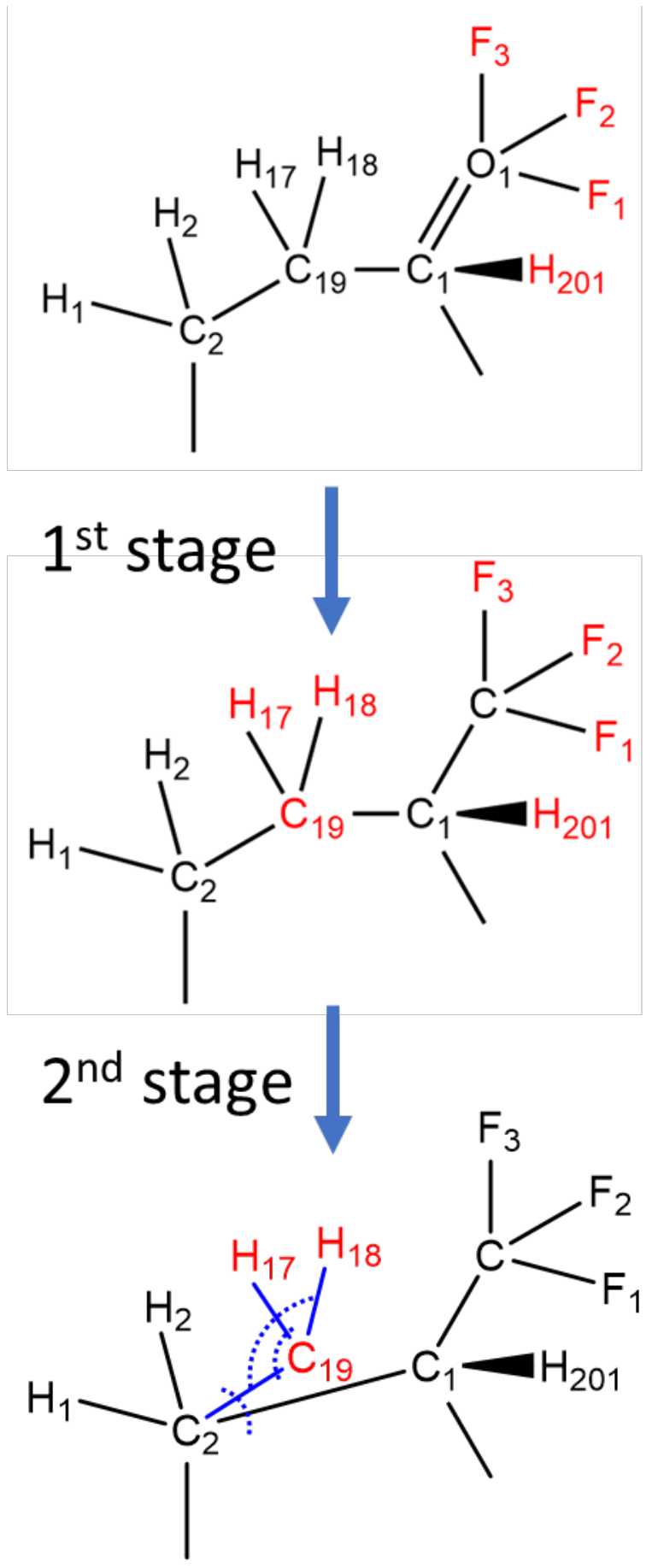

Figure S5. The two stages of perturbations for the ring contraction transformation ER $\alpha 3 \mathrm{~b}$ to 2d. F1, F2, F3, H201, H17, H18 and C19 in red indicates that they are dummy atoms. Atom $\mathrm{O} 1$ was perturbed into a carbon atom by changing its non-bonded interactions. The three blue lines indicate the three auxiliary bond restraints on C19-C2, H17-C19 and H18$\mathrm{C} 19$. The three blue arcs indicate the three auxiliary angle restraints on C19-C2-C1, H17C19-C2 and H18-C19-C2. 


\section{Linker contraction transformation}

The linker contraction transformation from CatS 35 to 132 (Fig. S6) adopts the same procedure as the ring contraction transformation from $\mathrm{ER} \alpha 3 \mathrm{~b}$ to $2 \mathrm{~d}$. No dummy atom was used for CatS 35 to 132. Change of non-bonded interactions, breaking of bonds and applications of bond/angle restraints were all initialized by changing parameters using prm.sh under each stage.

Using prm_control.sh instead of prm.sh can prepare the control calculation without auxiliary restraints described in the main text. The only difference between prm_control.sh and prm.sh is that during the $2^{\text {nd }}$ stage of contraction, bond a2-a3 was broken and bond a1-a3 was formed without any restraints. The control setup crashes at relaxation.

After preparing the system (001.setup/), equilibration (002.eq/), relaxation (003.prod/relax) and production (003.prod/) can be conducted. $\Delta \Delta \mathrm{G}$ values can be obtained from the free energy calculations in the complex state (com/) and the monomer state of ligand (mono/).

The following lambda values were used for CatS 35 to 132:

$$
\begin{aligned}
& 1^{\text {st }} \text { stage: } \quad 0.0000 .009220 .047940 .115050 .206340 .316080 .437380 .562620 .68392 \\
& 0.793660 .884950 .952060 .990780 .9950 .999 \\
& 2^{\text {nd }} \text { stage: } \quad 0.0000 .009220 .047940 .115050 .206340 .316080 .437380 .562620 .68392 \\
& 0.793660 .884950 .952060 .990780 .9950 .9991 .0
\end{aligned}
$$



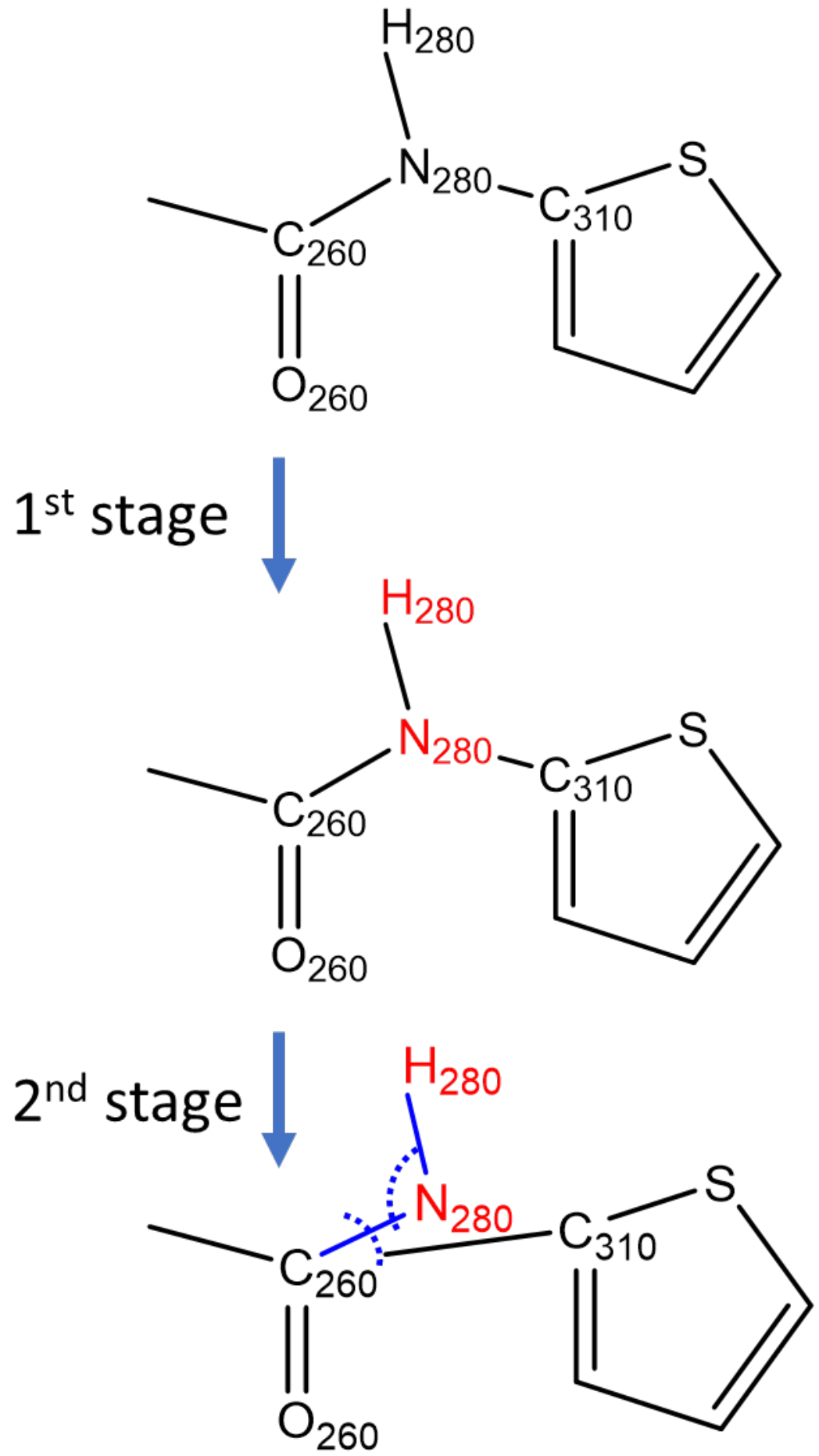

Figure S6. The two stages of perturbations for the ring contraction transformation CatS 35 to 132 . H280 and N280 in red indicate that they are dummy atoms. The two blue lines indicate the two auxiliary bond restraints applied on N280-C260 and H280-N280. The two dashed arcs indicate the two auxiliary angle restraints applied on N280-C260-C310 and H280-N280-C260. 


\section{Structures, input and output files}

Structures of ligands and proteins, XFF parameters for TPSB2 compounds, and the input and output files for the examples demonstrated using AMBER18 are available via the zip file included as supporting information. 


\section{References}

1. Huang, X.; Cheng, C. C.; Fischmann, T. O.; Duca, J. S.; Yang, X.; Richards, M.; Shipps, G. W., Discovery of a Novel Series of CHK1 Kinase Inhibitors with a Distinctive Hinge Binding Mode. ACS Med. Chem. Lett. 2012, 3 (2), 123-128.

2. Nagata, T.; Yoshino, T.; Haginoya, N.; Yoshikawa, K.; Nagamochi, M.; Kobayashi, S.; Komoriya, S.; Yokomizo, A.; Muto, R.; Yamaguchi, M.; Osanai, K.; Suzuki, M.; Kanno, H., Discovery of N-[(1R,2S,5S)-2-\{[(5-chloroindol-2-yl)carbonyl]amino\}-5(dimethylcarbamoyl)cyclohexyl]-5-methyl-4,5,6,7-tetrahydrothiazolo[5,4-c]pyridine-2carboxamide hydrochloride: A novel, potent and orally active direct inhibitor of factor Xa. Biorg. Med. Chem. 2009, 17 (3), 1193-1206.

3. Liang, G.; Choi-Sledeski, Y. M.; Shum, P.; Chen, X.; Poli, G. B.; Kumar, V.; Minnich, A.; Wang, Q.; Tsay, J.; Sides, K.; Kang, J.; Zhang, Y., A $\beta$-tryptase inhibitor with a tropanylamide scaffold to improve in vitro stability and to lower hERG channel binding affinity. Bioorg. Med. Chem. Lett. 2012, 22 (4), 1606-1610.

4. Winneroski, L. L.; Schiffler, M. A.; Erickson, J. A.; May, P. C.; Monk, S. A.; Timm, D. E.; Audia, J. E.; Beck, J. P.; Boggs, L. N.; Borders, A. R.; Boyer, R. D.; Brier, R. A.; Hudziak, K. J.; Klimkowski, V. J.; Garcia Losada, P.; Mathes, B. M.; Stout, S. L.; Watson, B. M.; Mergott, D. J., Preparation and biological evaluation of conformationally constrained BACE1 inhibitors. Biorg. Med. Chem. 2015, 23 (13), 3260-3268.

5. $\quad$ Richardson, T. I.; Dodge, J. A.; Durst, G. L.; Pfeifer, L. A.; Shah, J.; Wang, Y.; Durbin, J. D.; Krishnan, V.; Norman, B. H., Benzopyrans as selective estrogen receptor $\beta$ agonists (SERBAs). Part 3: Synthesis of cyclopentanone and cyclohexanone intermediates for $\mathrm{C}$-ring modification. Bioorg. Med. Chem. Lett. 2007, 17 (17), 4824-4828.

6. Bembenek, S. D., Ameriks, M.K., Mirzadegan, T., Yang, H., Shao, C., Burley, S.K., Crystal structure of human Cathepsin-S with bound ligand. 2017.

7. Nie, Z.; Perretta, C.; Erickson, P.; Margosiak, S.; Almassy, R.; Lu, J.; Averill, A.; Yager, K. M.; Chu, S., Structure-based design, synthesis, and study of pyrazolo[1,5-a][1,3,5]triazine derivatives as potent inhibitors of protein kinase CK2. Bioorganic \& Medicinal Chemistry Letters 2007, 17 (15), 4191-4195.

8. $\quad$ Stachel, S. J.; Coburn, C. A.; Steele, T. G.; Crouthamel, M.-C.; Pietrak, B. L.; Lai, M.-T.; Holloway, M. K.; Munshi, S. K.; Graham, S. L.; Vacca, J. P., Conformationally biased P3 amide replacements of $\beta$-secretase inhibitors. Bioorganic \& Medicinal Chemistry Letters 2006, 16 (3), 641-644.

9. Kettle, J. G.; Alwan, H.; Bista, M.; Breed, J.; Davies, N. L.; Eckersley, K.; Fillery, S.; Foote, K. M.; Goodwin, L.; Jones, D. R.; Käck, H.; Lau, A.; Nissink, J. W. M.; Read, J.; Scott, J. S.; Taylor, B.; Walker, G.; Wissler, L.; Wylot, M., Potent and Selective Inhibitors of MTH1 Probe Its Role in Cancer Cell Survival. J. Med. Chem. 2016, 59 (6), 2346-2361.

10. Tao, Z.-F.; Wang, L.; Stewart, K. D.; Chen, Z.; Gu, W.; Bui, M.-H.; Merta, P.; Zhang, H.; Kovar, P.; Johnson, E.; Park, C.; Judge, R.; Rosenberg, S.; Sowin, T.; Lin, N.-H., Structure-Based Design, Synthesis, and Biological Evaluation of Potent and Selective Macrocyclic Checkpoint Kinase 1 Inhibitors. J. Med. Chem. 2007, 50 (7), 1514-1527.

11. Zapf, C. W.; Bloom, J. D.; Li, Z.; Dushin, R. G.; Nittoli, T.; Otteng, M.; Nikitenko, A.; Golas, J. M.; Liu, H.; Lucas, J.; Boschelli, F.; Vogan, E.; Olland, A.; Johnson, M.; Levin, J. I., Discovery of a stable macrocyclic o-aminobenzamide Hsp90 inhibitor which significantly decreases tumor volume in a mouse xenograft model. Bioorg. Med. Chem. Lett. 2011, 21 (15), 4602-4607.

12. Baxter, E. W.; Conway, K. A.; Kennis, L.; Bischoff, F.; Mercken, M. H.; De Winter, H. L.; Reynolds, C. H.; Tounge, B. A.; Luo, C.; Scott, M. K.; Huang, Y.; Braeken, M.; Pieters, S. M. A.; 
Berthelot, D. J. C.; Masure, S.; Bruinzeel, W. D.; Jordan, A. D.; Parker, M. H.; Boyd, R. E.; Qu, J.; Alexander, R. S.; Brenneman, D. E.; Reitz, A. B., 2-Amino-3,4-dihydroquinazolines as Inhibitors of BACE-1 ( $\beta$-Site APP Cleaving Enzyme): Use of Structure Based Design to Convert a Micromolar Hit into a Nanomolar Lead. Journal of Medicinal Chemistry 2007, 50 (18), 4261-4264.

13. Suda, A.; Koyano, H.; Hayase, T.; Hada, K.; Kawasaki, K.-i.; Komiyama, S.; Hasegawa, K.; Fukami, T. A.; Sato, S.; Miura, T.; Ono, N.; Yamazaki, T.; Saitoh, R.; Shimma, N.; Shiratori, Y.; Tsukuda, T., Design and synthesis of novel macrocyclic 2-amino-6-arylpyrimidine Hsp90 inhibitors. Bioorg. Med. Chem. Lett. 2012, 22 (2), 1136-1141.

14. Fujinaga, M.; Sielecki, A. R.; Read, R. J.; Ardelt, W.; Laskowski, M.; James, M. N. G., Crystal and molecular structures of the complex of $\alpha$-chymotrypsin with its inhibitor Turkey ovomucoid third domain at 1.8 Å resolution. J. Mol. Biol. 1987, 195 (2), 397-418.

15. Huang, K.; James, M. N. G.; Lu, W.; Laskowski, M.; Anderson, S., Water molecules participate in proteinase-inhibitor interactions: Crystal structures of Leu18, Ala18, and Gly18variants of turkey ovomucoid inhibitor third domain complexed withStreptomyces griseusproteinase B. Protein Sci. 1995, 4 (10), 1985-1997.

16. Bode, W.; Wei, A. Z.; Huber, R.; Meyer, E.; Travis, J.; Neumann, S., X-ray crystal structure of the complex of human leukocyte elastase (PMN elastase) and the third domain of the turkey ovomucoid inhibitor. The EMBO Journal 1986, 5 (10), 2453-2458.

17. Horn, J. R.; Ramaswamy, S.; Murphy, K. P., Structure and Energetics of Protein-Protein Interactions: The Role of Conformational Heterogeneity in OMTKY3 Binding to Serine Proteases. J. Mol. Biol. 2003, 331 (2), 497-508.

18. Case, D. A.; Ben-Shalom, I. Y.; Brozell, S. R.; Cerutti, D. S.; Cheatham, T. E.; Cruzeiro, I., V. W. D.; Darden, T. A.; Duke, R. E.; Ghoreishi, D.; Gilson, M. K.; Gohlke, H., AMBER 2018. University of California, San Francisco, 2018.

19. Zhixiong, L.; Junjie, Z.; Chunwang, P.; Shuai, L.; Zhipeng, L.; Xiao, W.; Dong, F.; Jian, Y.; Gianpaolo, G.; Yongpan, C.; Jian, M.; Shuhao, W.; Peiyu, Z.; Mingjun, Y., A cloud computing platform for scalable relative and absolute binding free energy prediction: New opportunities and challenges for drug discovery. ChemRxiv, 2020.

20. Zou, J.; Tian, C.; Simmerling, C., Blinded prediction of protein-ligand binding affinity using Amber thermodynamic integration for the 2018 D3R grand challenge 4. J. Comput.-Aided Mol. Des. 2019, 33 (12), 1021-1029.

21. Kaus, J. W.; Pierce, L. T.; Walker, R. C.; McCammont, J. A., Improving the efficiency of free energy calculations in the Amber molecular dynamics package. J Chem Theory Comput 2013, 9 (9), 4131-4139.

22. ParmEd:Cross-program parameter and topology file editor and molecular mechanical simulator engine. https://github.com/ParmEd/ParmEd.

23. Zou, J.; Simmerling, C.; Raleigh, D. P., Dissecting the energetics of intrinsically disordered proteins via a hybrid experimental and computational approach. J. Phys. Chem. B 2019, 123 (49), 10394-10402.

24. Lenselink, E. B.; Louvel, J.; Forti, A. F.; van Veldhoven, J. P. D.; de Vries, H.; MulderKrieger, T.; McRobb, F. M.; Negri, A.; Goose, J.; Abel, R.; van Vlijmen, H. W. T.; Wang, L.; Harder, E.; Sherman, W.; ljzerman, A. P.; Beuming, T., Predicting binding affinities for GPCR ligands using free-energy perturbation. ACS Omega 2016, 1 (2), 293-304. 